\section{Combined Effect of lodine Contrast Media, Cisplatin and External Beam Radiotherapy on Anaplastic Thyroid Cancer Cells}

\author{
Nadi S. ${ }^{1}$, Shabestani Monfared A. ${ }^{2 *}$, Zabihi E. ${ }^{3}$, \\ Mahmoudzadeh A. ${ }^{4}$, Eyvazzadeh N. ${ }^{5}$, Tahamtan R. ${ }^{6}$
}

\begin{abstract}
Introduction: The current study investigated the combination of high $\mathrm{Z}$ atoms (iodine-, platinium-based drugs) with using low energy irradiation (120kvp) in Anaplastic Thyroid cancer cells.
\end{abstract}

Material and Methods: For this purpose, eight groups were designed: control (CNT), different concentrations of Iodine contrast media (ICM), irradiation with various doses, Cis-platin (CDDP) with different concentrations, (ICM + CDDP), (ICM + $\mathrm{RAD}),(\mathrm{CDDP}+\mathrm{RAD})$ and $(\mathrm{ICM}+\mathrm{CDDP}+\mathrm{RAD})$. The viability was measured by MTT and Colony assay. In MTT assay, the viability of 8305 c cells RAD (2 Gy)+ICM $(10 \mathrm{mg} / \mathrm{mL})$ group was significantly lower than those treated with RAD or ICM alone. $\mathrm{CDDP}+\mathrm{ICM}+\mathrm{RAD}$ group significantly decreased the viability. In colony assay, cells in ICM + RAD (2 Gy) group reduced the number of colonies more significant than RAD group. The difference of colony forming ability between CDDP and CDDP + RAD (2 Gy) was significant. The difference of ICM + CDDP + RAD (2 Gy) and CDDP + RAD (2 Gy) group was significant. All data were statistically analysed using one-way analysis of variance (ANOVA) followed by Chafe's multi-comparisons tests. All data were presented as mean \pm standard deviation (SD) and analysed using statistical package for social sciences (SPSS 16). Significance was considered to be $\mathrm{p}<0.05$.

Results: In MTT assay, the viability of 8305c cells RAD (2 Gy) + ICM (10mg/ $\mathrm{mL}$ ) group was significantly lower than those treated with RAD or ICM alone. CDDP $+\mathrm{ICM}+\mathrm{RAD}$ group significantly decreased the viability. In colony assay, cells in ICM + RAD (2 Gy) group reduced the number of colonies more significantly than RAD group. The difference of colony forming ability between CDDP and CDDP + RAD (2 Gy) was significant. The difference of ICM + CDDP + RAD (2 Gy) and CDDP + RAD (2 Gy) group was significant.

Conclusion: Exposure of ATC to ICM in the presence of CDDP increases tissue $\mathrm{X}$-rays absorbance by Auger electrons and photo electrons leading to more fatal effects against the tumour.

\section{Keywords}

Anaplastic Thyroid Carcinoma, Radiotherapy, Cisplatin, lodine Contrast Media, Photoelectric

\section{Introduction}

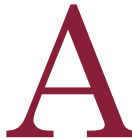

naplastic thyroid carcinoma (ATC) is categorized as a malignant endocrine tumour which has recently been grown up on large scale in the world. Its prognosis is poor and mostly affected
${ }^{1} \mathrm{MSc}$ Student of Radio-

biology and Radiation

Protection, Cellular

and Molecular Biology

Research Centre, Babol

University of Medical Sci-

ences, Babol, Iran

2Professor of Medical

Physics, Cellular and Mo

lecular Biology Research

Centre, Babol University

of Medical Sciences,

Babol, Iran

${ }^{3}$ PharmD, Phd, Cellular

and Molecular Biology

Research Centre, Babol

University of Medical Sci

ences, Babol, Iran

4Phd Immunology,

Department of Biosci-

ence and Biotechnology

Malek-Ashtar University

of Technology. Tehran,

Iran

${ }^{5}$ Phd of medical physic,

Radiation Research

Center, Faculty of Para-

medicine, Aja University

of Medical Sciences,

Tehran, Iran

${ }^{6} \mathrm{MSc}$ of Radiobiology

and Radiation Protec-

tion, Babol University

of Medical Sciences,

Babol, Iran

*Corresponding author:

A. Shabestani Monfared

Ganj-Afrooz Avenue,

Babol University of Medi-

cal Sciences, Depart-

ment of Biochemistry

And Biophysics, Babol,

Iran

E-mail: a.monfared.sh@

gmail.com

Received: 18 March 2016

Accepted: 12 July 2017 
patients die in few months following its diagnosis. The current therapy procedure includes multiple approaches where combines surgery, radiotherapy, radio chemotherapy and chemotherapy $[1,2]$. Unlike other types of thyroid cancers, the radioactive iodine (RAI) has not been reported to have a significant therapeutic role in patients with anaplastic carcinoma [3]. The ultimate goal of radiation therapy is the delivery of a high therapeutic dose of ionizing radiation to the tumour cells without exceeding the normal tissue tolerance. Several kinds of methods with different success levels have been investigated in order to produce highly localized dose distributions. Some conventional techniques are boron neutron capture therapy, stereotactic radiotherapy, intensity-modulated radiation therapy and X-ray phototherapy are few examples for such treatments $[4,5]$.

In X-ray phototherapy method, tumour needs to be loaded with an iodinated contrast medium (CM) and is exposed to X-rays in kilo voltage range (lower than $150 \mathrm{kV}$ ). Consequent to these absorbed energies, substantial photoelectric interactions are produced by high photoelectric cross-section of iodine. These substantial photoelectric interactions generate fluorescent X-rays, photoelectrons and Auger electrons. These interactions could enhance X-ray dose deposition inside the tumour [4].

Chemotherapy is one of the most interesting topics among thyroid cancer researches. Generally, among all chemotherapeutic agents, platinum-based drugs such as CDDP play an important role in the treatment of solid tumours; however, their clinical use has been restricted because of their toxicity after systemic administration. Thus, a balance between neurotoxicity and therapeutic efficacy should be considered [6]. CDDP crosslinks between two DNA strands in different ways interfering with cell division by mitosis, indeed, affected the proliferation rate of each cell line $[7,8]$. It could be useful in delivering high $-\mathrm{Z}$ material to cells which improves the absorption of irradiation especially around an optimal energy [8]. The present study attempts to investigate the biological effects of a combination of X-ray phototherapy and chemotherapy with CDDP on anaplastic thyroid cancer cells for the first time.

\section{Material and Methods}

\section{Experimental Design}

Human anaplastic thyroid carcinoma cell line (8305c); the cells were cultured in DMEM medium (Gibco) supplemented with $10 \%$ fetal bovine serum (FBS, Gibco) and 1\% Pen Strep ${ }^{\circledR}$ solution (Sigma). The cells were maintained at $37^{\circ} \mathrm{C}$ in a humidified incubator with $5 \% \mathrm{CO}_{2}$.

In this study eight groups were designed:

1- CNT: cells were not treated with RAD, ICM and CDDP

2- ICM: cells were treated with different concentrations of $\operatorname{ICM}(0.5,10,25,50$ and $100 \mathrm{mg}$ iodine $/ \mathrm{mL}$ )

3- RAD: cells were treated with various doses of radiation $(0.5,1,1.5$ and $2 \mathrm{~Gy})$

4-Cis-Diammine dichloro platinum (II) CDDP : cells were treated with different concentration of $\operatorname{CDDP}(5,10,20 \mu \mathrm{g} / \mathrm{mL})$

5- ICM + CDDP: cells were treated with, ICM in concentration of $(10 \mathrm{mg}$ iodine $/ \mathrm{mL})$ and CDDP $(5 \mu \mathrm{g} / \mathrm{mL})$

6- ICM + RAD: cells were exposed to various dose of radiation $(0.5,1,1.5$ and $2 \mathrm{~Gy})$, in the present of ICM in concentration of $(10 \mathrm{mg}$ iodine $/ \mathrm{mL}$ )

7- CDDP + RAD: cells were exposed to various dose of radiation $(0.5,1,1.5$ and $2 \mathrm{~Gy})$ in the present of CDDP $(5 \mu \mathrm{g} / \mathrm{mL})$

8- ICM + CDDP + RAD: cells were treated with varied doses of radiation $(0.5,1,1.5$ and $2 \mathrm{~Gy})$ in the present of ICM in concentration of $(10 \mathrm{mg}$ iodine $/ \mathrm{mL})$ and CDDP $(5 \mu \mathrm{g} / \mathrm{mL})$.

\section{Materials and Reagents}

Giemsa stain (0.4\%) and MTT (3-(4, 5-dimethyl-thiazol-2-yl)-2, 5-diphenyl tetrazo- 
lium bromide) were purchased from SigmaAldrich Co. (UK). The iso-osmolar contrast medium, Iodixanol $(320 \mathrm{mg} / \mathrm{mL}$, Visipaque, GE Healthcare). Cisplatin was purchased from Mylan Chemical Company, France.

\section{Irradiations}

Cells in groups 3, 6, 7 and 8 were irradiated with Orthovoltage Unit (Stabilipan Siemens, Germany) at low energy (120keV), a dose rate of $186.16 \mathrm{cGy} / \mathrm{min}$, over an area of $12 \times 8$ $\mathrm{cm}^{2}, 30 \mathrm{~cm}, 4 \mathrm{~mm}$ Aluminum filter, at $30 \mathrm{~cm}$ FSD. The condition of cells during the radiation procedure was at room temperature. And the cells with or without irradiation were put under the same conditions.

\section{Proliferation Tests}

Tetrazulium (MTT) Assay

Cells were seeded in 96-well plates $(10 \times 103$ cells/well); treatment was performed for 2 hours with different concentrations of ICM $(0.5,10,25,50$ and $100 \mathrm{mg}$ iodine $/ \mathrm{mL})$ or $\operatorname{CDDP}(5,10,20 \mu \mathrm{g} / \mathrm{mL})$ in the complete medium (DMEM supplemented with 10\% FBS and $1 \%$ Pen Strep). Also different doses of Xray $(0.5,1,1.5$ and 2 Gy) were irradiated to the samples. Furthermore, combination of ICM (10 $\mathrm{mg}$ iodine $/ \mathrm{ml}$ ) and CDDP $(5 \mu \mathrm{g} / \mathrm{mL})$ was used without, and with different doses of $\mathrm{X}$ ray $(0.5,1,1.5$ and 2 Gy) during the cells treated for 2 hours, after that medium was removed then washed with HBSS and fresh media was added. After 48hours, $15 \mu \mathrm{L}$ of MTT solution (3-(4, 5-dimethyl-thiazol-2-yl)-2, 5-diphenyltetrazolium bromide (Sigma-Aldrich, St. Louis, MO, USA) ( $5 \mathrm{mg} / \mathrm{mL})$ was added into each well and the plates were incubated at $37^{\circ} \mathrm{C}$ for $3.5 \mathrm{hr}$. Medium was removed, and $100 \mu \mathrm{l}$ DMSO was added to each well to solubilize the formazan crystals and the optical density was measured using a microplate-reader (Ryto RT-2100, China) at $570 \mathrm{~nm}$ wavelength. Percentage of cell viability was calculated as follows:

Cell viability $(\%)=$ Test optical density /
Control optical density $\times 100$

The assay was performed in triplicate.

\section{Colony Formation Assay}

Cells were treated in different groups with CDDP $(5 \mu \mathrm{g} / \mathrm{ml})$ or ICM $(10 \mathrm{mg}$ iodine $/ \mathrm{ml})$, or different doses of $\operatorname{RAD}(0.5,1,1.5,2 \mathrm{~Gy})$ separately, also in combination groups (ICM + CDDP), (ICM + RAD $),($ CDDP + RAD) in different groups, and again combination (ICM + CDDP) with RAD.Cells treatment was performed for 2 hours and exposure to RAD was at same time. After incubation time, Sub-confluent monolayer cells were washed with PBS twice then, were trypsinized and collected in growth medium containing serum. The cells were centrifuged (200g, $5 \mathrm{~min}$ ) and were resuspended in fresh growth medium. Dilution of 1000 cells $/ \mathrm{mL}$ were prepared after counting with hemocytometer, and seeded in petri dishes as triplicate. The petries were incubated in $37^{\circ}$ for 2 weeks. Fresh medium was added to the petries after 1 week. To count the number of colonies, medium was removed, and washed with PBS solution ( $\mathrm{pH} 7.4)$. Colonies were fixed with glutaraldehyde $(6.0 \% \mathrm{v} / \mathrm{v})$, stained with Giemsa $(0.4 \%)$ and the number of colonies were assessed by microscopic counting. The colonies with at least 50 cells were counted. The colony-forming efficiency (CFE) of each cell line was obtained, which was calculated as:

CFE $(\%)=$ number of colonies/initial seeding density $\times 100$.

The plating efficiency in this method was about $3.9 \%$. The data are expressed as colonyforming capacity, which represent the number of colonies in each petri after initial seeding.

\section{Statistical Analysis}

All data were statistically analysed using one-way analysis of variance (ANOVA) followed by Chafe's multi-comparisons tests. All data were presented as mean \pm standard deviation (SD) and analysed using statistical package for social science (SPSS 16). Significance level was considered to be $\mathrm{p}<0.05$. 


\section{Results}

\section{MTT Assays}

Viability of the cells in all seven groups compared with CNT group has been represented in Figures 1, 2 and 3. To determine significant cytotoxic effect in the final culture medium, cells were treated 2 hours with five concentrations of $\operatorname{ICM}(5,10,25,50$ and $100 \mathrm{mg}$ iodine/ $\mathrm{ml}$ ) (Figure 1C). ICM has been extensively used for radio diagnosis in safely doses, so that we must choose the dose without cytotoxicity. Between 5 different doses, just $100 \mathrm{mg} /$ $\mathrm{ml}$ was a significant decrease in viability compared with control. In our protocol, we must choose a safe dose. Based on previous studies, $10 \mathrm{mg}$ iodine $/ \mathrm{ml}$ in all treatment groups was chosen $[9,10]$, and is higher than doses currently used in diagnosis.

No significant decrease was found in viability of the cells 48 hours after using different doses of radiation (Figure 1A).

The viability of $8305 \mathrm{C}$ cells after a 2 -hour exposure to different concentrations of CDDP $(5,10,20 \mu \mathrm{g} / \mathrm{ml})$ decreased to $96.7 \%$ (P-value $\leq 0.01), 92.7 \%$ (P-value $\leq 0.001)$ and $71.4 \%$ (P-value $\leq 0.001)$, respectively as compared to CNT (Figure 1B). In this study, we used $5 \mu \mathrm{g} /$ $\mathrm{ml}$ of CDDP as the lowest cytotoxic concentration in combination tests, in order to investigate synergism effect. Also, (ICM + CDDP)
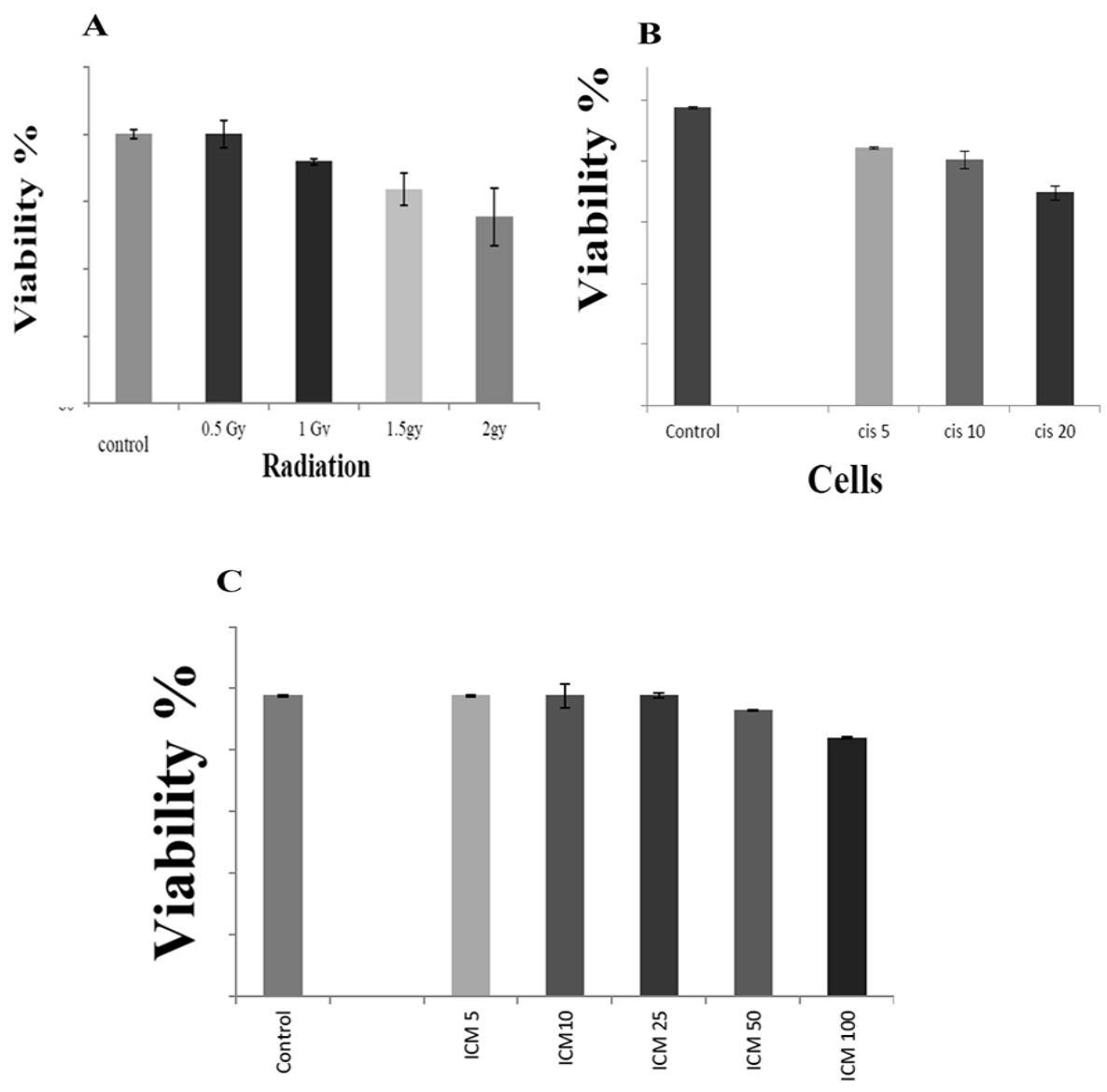

Cells

Figure 1: MTT assay.(A) cell viability after exposure to RAD. (B) viability of cells after exposed with CDDP . (C) viability of cells after exposed withICM.

Mean \pm SD: $* P<0.05, * * P<0.01, * * * P<0.001$. 
did not significantly change the viability compared with CDDP alone.

As well, combining ICM (10 mg iodine/ml) + RAD (2Gy) decreased the viability $(86.6 \%$, $\mathrm{P}$-value $\leq 0.001)$ at 48 hours post exposure compared with CNT group (Figure 2A).

Different doses of radiation $(0.5,1,1.5$ and 2 Gy) could potentiate CDDP $(5 \mu \mathrm{g} / \mathrm{ml})$ cytotoxic effect in a dose dependent manner. The viability of different radiation doses was $86.2 \%$, $84 \%, 81.1 \%$ and $78.2 \%$, respectively (Figure 2B).

Combining exposure to CDDP $(5 \mu \mathrm{g} / \mathrm{ml})$
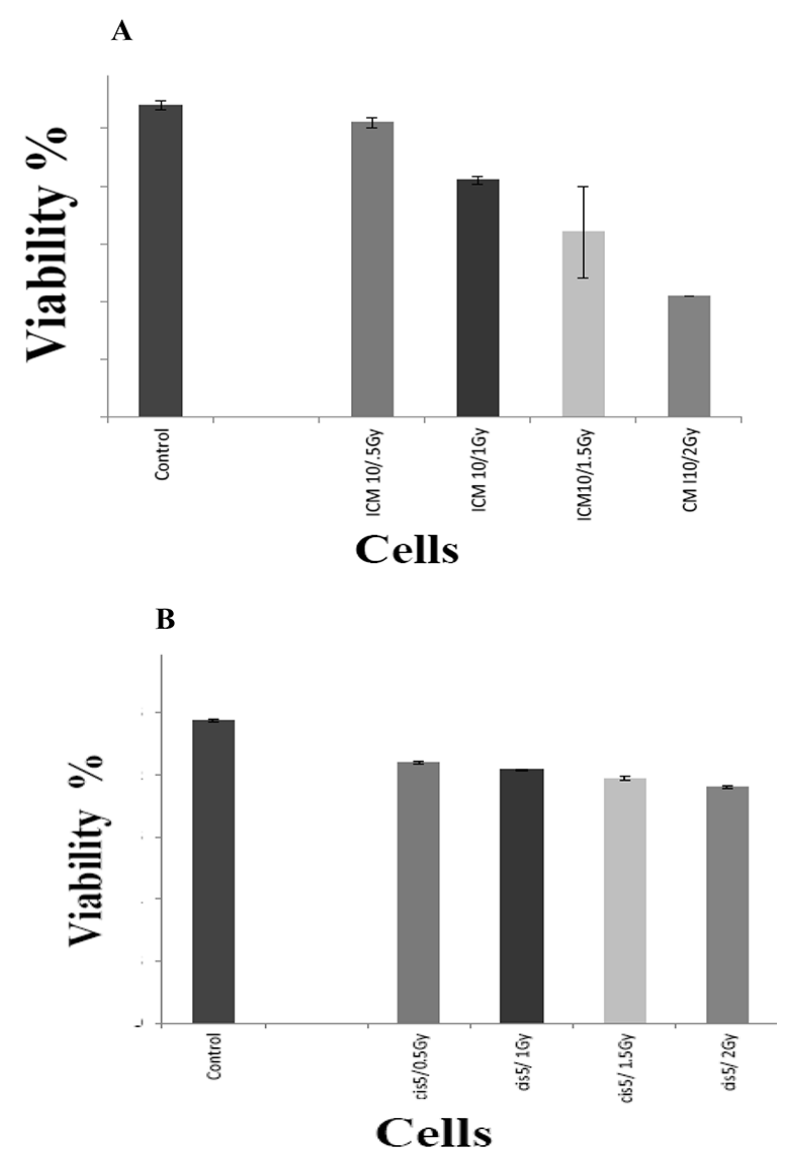

Figure 2: MTT assay. (A) Viability of cells exposed at ICM combinations with Radiation compared with control. (B) Viability of cells exposed to CDDP combined with Radiation in different doses, compared with control Mean \pm SD: $* * * P<0.001$. with ICM $(10 \mathrm{mg} / \mathrm{ml})$ and different doses of radiation $(0.5,1,1.5,2 \mathrm{~Gy})$ significantly decreased the viability after 48 hours $(85.4 \%$, $80.2 \%, 75.1 \%$, and $71.1 \%$, respectively).

As previously mentioned in MTT assay, some results are noticeable. Briefly, ICM in $10 \mathrm{mg} / \mathrm{ml}$, CDDP $(5 \mu \mathrm{g} / \mathrm{ml})$, between different doses of RAD (2Gy) was chosen for combination groups. All results are shown in (Figure 3).

\section{Colony Forming Assay}

The results of colony assay obtained with different exposure regime are depicted in (Figure 4A). The colony-forming efficiency (CFE) in $6 \mathrm{~cm}$ petri dishes was $3.9 \%$ for cells. While exposure to ICM (10 mg iodine/ml) alone for two hours did not show any significant effects on colony counts compared with the CNT group. Exposure to CDDP alone $(5 \mu \mathrm{g} / \mathrm{ml})$ for $2 \mathrm{~h}$ would significantly decrease the colony counts. Furthermore, a significant decrease was seen in the 2Gy RAD group (Figure 4A).

There is no significant difference in survival fraction between ICM + CDDP group (65.79\%) and CDDP group (67.51\%) and also CDDP + RAD group in the doses lower than 2 Gy.

In ICM + RAD group, the number of colony decreased by increasing radiation dose $(0.5$, 1, 1.5, 2 Gy), and also survival fraction constantly decreased $(91.44 \%, 82.9 \%, 65.8 \%$ and $50.42 \%$ ) due to apoptosis effects of the combination treatment. The difference between RAD (2Gy) alone and ICM + RAD (2 Gy) group was significant, and the reduction of the number of colonies was notable (Figure 4B).

Combination of CDDP with radiation $(0.5$, $1,1.5$ and 2 Gy) induced lethality for anaplastic thyroid carcinoma 8305c cells. Although the decrease in number of colony was significant in all of the radiation doses, it was more noticeable in higher doses (Figure 4A).

The difference of colony forming ability between CDDP group and (CDDP + RAD) (2Gy) group was statistically significant ( $p$ 


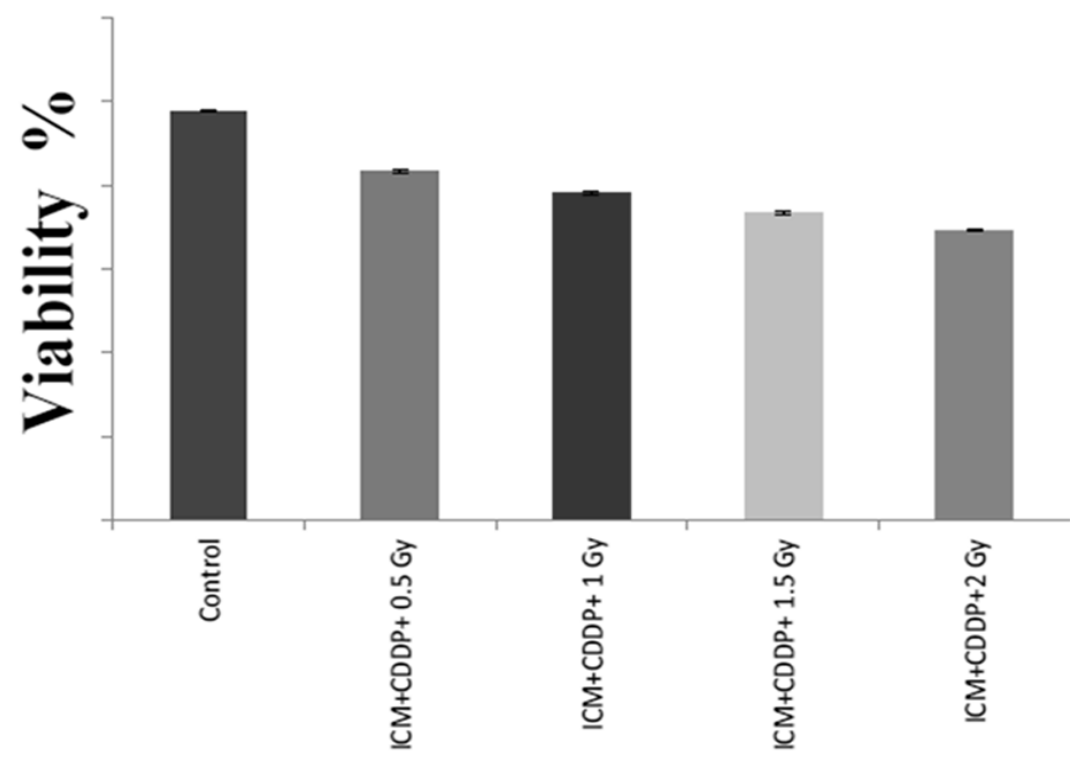

Figure 3: MTT Assay: Viability of cells exposed to Radiation In the present of CDDP and ICM. The controls are also represented on this histogram.

Mean \pm SD: ${ }^{* * *} \mathrm{P}<0$.

$\leq 0.001)$ (Figure 4B).

Considering colonogenic survival in CDDP $+\mathrm{ICM}+\mathrm{RAD}(0.5,1,1.5$ and 2 Gy) group, a significant decrease $(21.36 \%)$ was observed in 2 Gy radiation dose, but for the doses of $1.5,1$ and $0.5 \mathrm{~Gy}$, it was decreased to $32.47 \%$, $52.13 \%$ and $60.66 \%$, respectively (Figure 4A). The differences of colony assay between (CDDP + RAD) (2 Gy) group and (CDDP + ICM + RAD) (2 Gy) group were significant (Figure 4B).

\section{Discussion}

The emission of photoelectrons and Auger electrons (weakly bound electrons) result in the production of very high local ionization density. While Auger electrons travel much shorter distances typically $\sim 10 \mathrm{~nm}$, fluorescence photons can travel longer ranges (up to centimeters) [11]. Hence, a contrast enhancement in x-ray imaging normally is correlated with the emission of secondary radiation (photoelectrons, x-ray fluorescence, Auger electrons) based on the photoelectric effect, and also CDDP in exposure time to emit sec- ondary radiation. Accordingly, it will increase the energy absorption of the enhanced tissues located in short distance in the short distance. Because of the photoelectric effect along with the use of high $\mathrm{Z}$ elements, we tried to evaluate the therapeutic effects of radiation combined with CDDP as a chemotherapy drug and iodine contrast media (ICM) on cell line in order to obtain multimodal therapy.

Our findings demonstrated that 2 Gy radiation dose alone causes significant decrease $(70 \%)$ in the number of colonies counted in colony-formation assay (Figure 4A). But there is not any significant decrease in viability in all doses in MTT assay (Figure 1A). Due to insignificant damages that have occurred at low dosages, the proliferation will be affected but it will not cause cell death. It should be noted that MTT shows only acute effect. However, in colony there is enough time to detect these damages. Hence, it can be concluded that apoptosis as a delayed effect in colonyformation assay. Ohnishi et, al. [12] in their study showed the effectiveness of RAD in different doses ( 0 up to $6 \mathrm{~Gy}$ ), in colony forming 
assay that induced lethality for $8305 \mathrm{c}$ cells by increasing doses of radiation.

The results of MTT assay in different concentration of ICM showed a significant decrease in cell viability which were treated by ICM alone in concentration of $(100 \mathrm{mg} / \mathrm{ml})$. In our study, the incubation period for ICM was 2 hours which affected 14\% cell death. This finding is in accordance with Hizoh et al. [13]. At concentration of $111 \mathrm{mg}$ iodine $/ \mathrm{mL}$, they have reported that DNA breakage had been markedly elevated up to more than $60 \%$ as compared with our study on the same concentration but less time to incubation, death effect due to the fact that our selected cells were ATC $(8305 \mathrm{C})$, which are more resistant that their selected cells. It is, however, acceptable. In MTT assay, the cells viability depends on cytotoxicity, and it is not possible to measure cells proliferation but in colony assay the mitosis death of cells could be measured.

In colony assay, we have selected $10 \mathrm{mg} / \mathrm{ml}$ concentration due to the lack of the toxicity and viability decreased to $97 \%$. This has no statistical significance.

In this study, it was important to select a dose of ICM without apoptosis in the cells but with synergising effect in combination treatments.

In combination treatments, we used ICM combined with various doses of radiation. And it showed significant decrease in cell viability (87\%) measured by MTT assay in 2 Gy radiation dose. And if there is great difference with control group by increasing photoelectric effect along with ICM, the DNA damage will increase due to Auger electron and photo electrons release. It is also noticeable that the colony-forming assay showed a significant change only in high doses of irradiation (1.5, $2 \mathrm{~Gy}$ ) (Figure 4A). If cells have enough time to do mitosis activity, they could prolong apoptosis effect and it is in agreement with Corde et al. [9]. It indicates that SQ20B cells suspended in $10 \mathrm{mg} / \mathrm{ml}$ of radio-contrast media. The optimal X-ray energy for increasing the radiation energy absorption was $50 \mathrm{keV}$ according to clonogenic assay results. Therefore, the emission of secondary radiation in photoelectric effect could induce lethal damage; it shows significant similarity with our findings.

As well, in an in vivo study, Adam et al. [4] showed $44 \%$ increase in life span induced by injecting IV iodine and irradiation with $50 \mathrm{keV}$ monochromatic X-rays (10 Gy) in rats bearing F98 glioma. Based on this study, we investigated photoelectric effect in anaplastic thyroid carcinoma. They could be useful in delivering high- $Z$ material to cells improving the absorption of irradiation especially with the optimal energy [8]. And it supported by the fact that it is the mechanism involved in our findings.

CDDP induces DNA cross-links in different ways thus interferes with the mitosis, resulting in decreasing the proliferation rate of cell lines.

In our findings, various concentrations of CDDP could significantly reduce viability in MTT assay. In lower dose of $(5 \mu \mathrm{gr} / \mathrm{ml})$, the cell viability reduced to $87 \%$ which was significantly different from the control group. However, to achieve a synergistic effect of CDDP combined with radiation, lower doses of CDDP $(5 \mu \mathrm{gr} / \mathrm{ml})$ used in colony assay. It causes the lowest apoptosis by CDDP. This is the process to obtain the synergism effect of CDDP + RAD. In the study of Tirro et al. [14], the efficacy of CDDP with the concentration of $5 \mu \mathrm{gr} / \mathrm{ml}$ on ATC cells (8305C) was evaluated in three different time $(24,48$ and 72 ) hours. At 48 hours' time, CDDP led to significant decrease in the number of viable cells $[7,8]$. Cytotoxicity of RAD and CDDP was assessed by using clonogenic assays.

The addition of CDDP potentiated RAD effect and significantly enhanced cell killing effects of the CDDP alone [15]. Rouesseau et al. $[16,17]$ evaluated combination carboplatin and photon irradiation on F98 glioma-bearing rats. Their study showed that survival of the group of animals that had received platinated drugs alone, as increased the comparison with the group that just had received X-radiation. 
This combination of treatments (RAD + CDDP) was the most effective protocol, with $55 \%$ long-term survivors. So it can be concluded that combination treatment (RAD +CDDP) has a synergistic role in damages induced by radiation and increases the therapeutic efficacy. This group evaluated CDDP instead of carboplatin in another test and, it significantly enhanced the survival of F98 glioma-bearing rats [6]. Experiments on Combination therapy $\mathrm{RAD}$ and high $\mathrm{Z}$ atoms have been conducted only on glioma with Adam and his groups until now; however, our aim is to assess the in- crease of biological effects of the radiation in vitro in combination protocol with minimum damages to the healthy tissues.

The European Organization for Research and Treatment of Cancer Trial directly compared radiation alone with CDDP in the presence of radiation following surgery for the treatment of advanced head and neck cancer. 261 patients had participated in this trial and all of them initially had surgery. Almost half of the patients received just radiations while the other half received CDDP + RAD. After almost 5 years, progression-free survival was
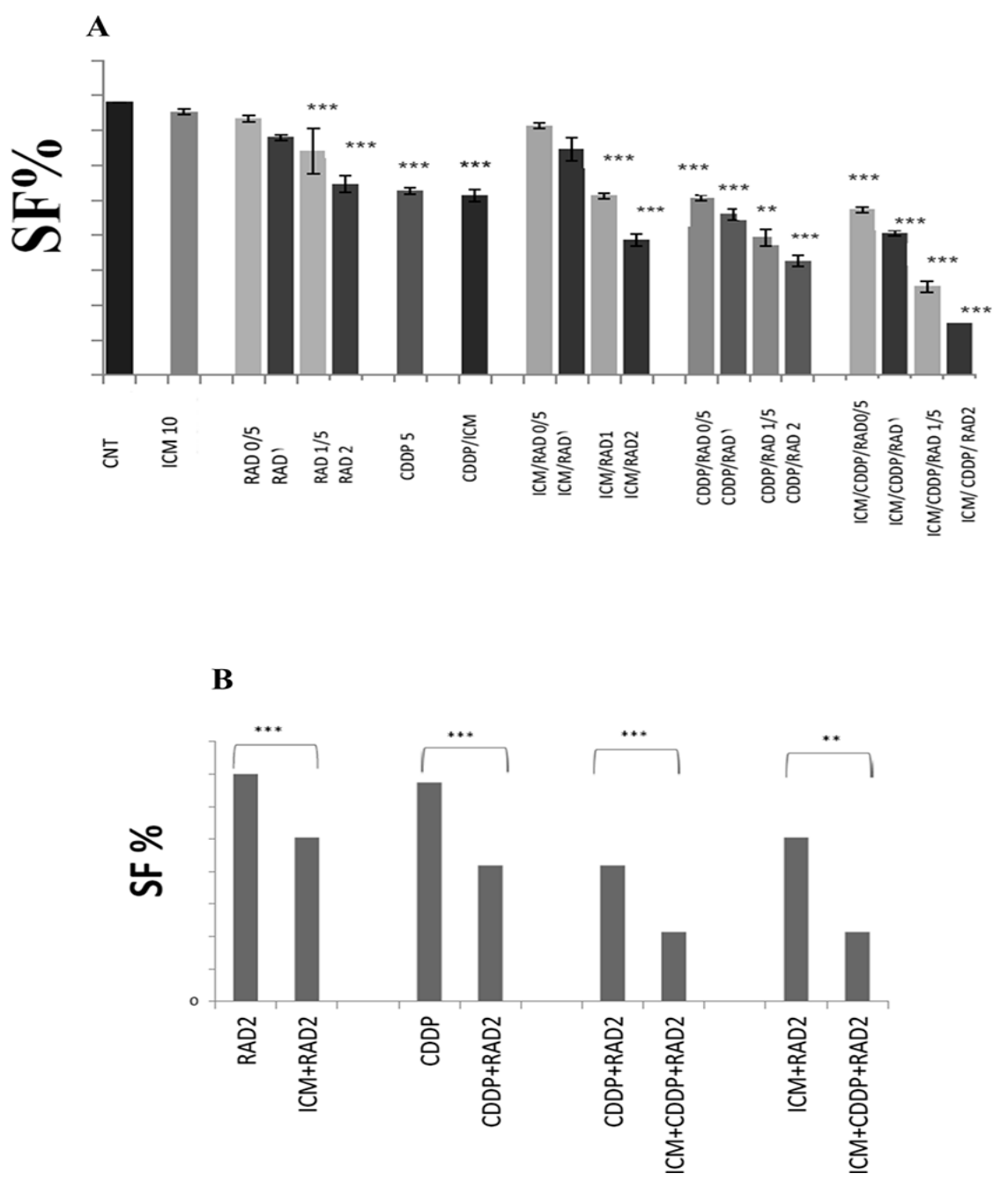

Figure 4: Colony assay (A) Survival in various modalities: ICM , RAD , CDDP, ICM + CDDP, ICM + $R A D, C D D P+R A D$ and RAD In the present of CDDP and ICM. The controls are also represented on this histogram. (B) Comparison to access synergism effect .

Mean $\pm \mathrm{SD}: * * \mathrm{P}<0.01 ; * * * \mathrm{P}<0.001$. 
$11 \%$ higher and overall survival rates were $13 \%$ higher in those who received combined therapy.

We also evaluated the synergistic effect of $\mathrm{ICM}+\mathrm{CDDP}+\mathrm{RAD}$. We have observed a decrease in the number of colony in all doses (Figure 4A). In comparing ICM + RAD (2Gy) and RAD (2Gy) groups, a significant decrease was seen in viability of the cells treated with ICM before 2 Gy radiation (Figure 4B). Therefore, ICM causes a synergising effect with radiation. Also, CDDP + RAD (2Gy) leads to a significant difference compared with CDDP alone, and we witness the accumulate effect (Figure 4B). Furthermore, combination of ICM and CDDP with RAD has a noticeable synergism effect compared with CDDP + RAD or ICM + RAD alone. Our results (Figure 4B) demonstrate that in lower radiation doses, the colony assay showed delay damages better than MTT assay in test time. It means that in each mitotic activity, the number of cells that could not repair damages will be removed from the cell cycle. However in MTT, we just see acute effect because of auger electrons and photoelectrons as secondary radiations enhanced absorbed dose and prolong apoptosis.

Adam et al. [4, 5, 8, 9, 18, 19] studied on the development of SSR technique in glioma management for many years. To induce photoelectric effect, combination of ICM, CDDP and RAD are necessary to succeed in this technique. The optimal energy for ICM is $50 \mathrm{keV}$ while it is $78.8 \mathrm{keV}$ for CDDP. In their study, the irradiated rats in the presence of CDDP had a significant longer survival than CDDP alone. Moreover, a significant decrease in the early death was seen among the rats irradiated in the presence of ICM than without ICM but it was lower than CDDP [8]. Our study showed that the survival of cells treated in ICM + RAD (2Gy) in colony assay was lower than CDDP. These findings are different from Adam et al. study. Their group used synchrotron source and monochromatic energy with optimal energy while we used orthovoltage machine with
$120 \mathrm{kev}$. with maximum energy near $\mathrm{K}$ edge of iodine.

In summary, our results confirm that the effect of Auger electrons is greater in medium and high $\mathrm{Z}$ atoms. Furthermore, the emitting atoms must be in closest distance from the target molecule to be damaged (double-strand breaks) [9].

\section{Conclusion}

It is not possible to increase dose to achieve the highest wield in chemotherapy and radiotherapy as the based known practices in cancer treatment. It is due to the damaging effects on normal cells surrounded by cancerous ones.

Chemotherapy might be more effective in comparison with radiotherapy but it has more toxicity effect and long term application. Therefore, a combined practice that could increase the efficacy of radiotherapy without increasing the doses is recommended.

The photoecectic effect will result in high z element of cddp and icm provided that they are radiated by low energy $\mathrm{X}$ ray.

\section{Acknowledgment}

This work was financially supported by Babol University of Medical Sciences research affairs. We also would like to thank Rajaee Oncology Hospital radiotherapy and Physics staff for their kind assistance.

\section{Conflict of Interest}

None

\section{References}

1. Dumke AK, Pelz T, Vordermark D. Long-term results of radiotherapy in anaplastic thyroid cancer. Radiat Oncol. 2014;9:90. doi.org/10.1186/1748717X-9-90. PubMed PMID: 24685141. PubMed PMCID: 3994242.

2. Stavas MJ, Shinohara ET, Attia A, Ning MS, Friedman JM, Cmelak AJ. Short course high dose radiotherapy in the treatment of anaplastic thyroid carcinoma. J Thyroid Res. 2014;2014:764281. doi.org/10.1155/2014/764281. PubMed PMID: 25379320. PubMed PMCID: 4213987. 
3. Powell C, Newbold K, Harrington KJ, Bhide SA, Nutting CM. External beam radiotherapy for differentiated thyroid cancer. Clin Oncol (R Coll Radiol). 2010;22:456-63. doi.org/10.1016/j. clon.2010.03.012. PubMed PMID: 20427166.

4. Adam JF, Biston MC, Joubert A, Charvet AM, Le Bas JF, Esteve F, et al. Enhanced delivery of iodine for synchrotron stereotactic radiotherapy by means of intracarotid injection and blood-brain barrier disruption: quantitative iodine biodistribution studies and associated dosimetry. Int $J$ Radiat Oncol Biol Phys. 2005;61:1173-82. doi.org/10.1016/j. ijrobp.2004.12.026. PubMed PMID: 15752899.

5. Adam JF, Joubert A, Biston MC, Charvet AM, Peoc'h M, Le Bas JF, et al. Prolonged survival of Fischer rats bearing F98 glioma after iodine-enhanced synchrotron stereotactic radiotherapy. Int J Radiat Oncol Biol Phys. 2006;64:603-11. doi. org/10.1016/j.jirobp.2005.09.004. PubMed PMID: 16338098.

6. Lapouge G, Millon R, Muller D, Abecassis J, Eber $\mathrm{M}$, Bergerat JP, et al. Cisplatin-induced genes as potential markers for thyroid cancer. Cell Mol Life Sci. 2005;62:53-64. doi.org/10.1007/s00018-0044329-z. PubMed PMID: 15619007.

7. Rousseau J, Barth RF, Fernandez M, Adam JF, Balosso J, Esteve F, et al. Efficacy of intracerebral delivery of cisplatin in combination with photon irradiation for treatment of brain tumors. J Neurooncol. 2010;98:287-95. doi.org/10.1007/s11060009-0074-3. PubMed PMID: 20012464. PubMed PMCID: 3375241.

8. Adam JF, Biston MC, Rousseau J, Boudou C, Charvet AM, Balosso J, et al. Heavy element enhanced synchrotron stereotactic radiotherapy as a promising brain tumour treatment. Phys Med. 2008;24:927. doi.org/10.1016/j.ejmp.2008.02.003. PubMed PMID: 18407772.

9. Corde S, Joubert A, Adam JF, Charvet AM, Le Bas $J F$, Esteve $F$, et al. Synchrotron radiation-based experimental determination of the optimal energy for cell radiotoxicity enhancement following photoelectric effect on stable iodinated compounds. $\mathrm{Br} J$ Cancer. 2004;91:544-51. doi.org/10.1038/ sj.bjc.6601951. PubMed PMID: 15266326. PubMed PMCID: 2409846.

10. Esteve F, Corde S, Elleaume $\mathrm{H}$, Adam JF, Joubert $A$, Charvet AM, et al. Enhanced radio sensitivity with iodinated contrast agents using monochromatic synchrotron X-rays on human cancerous cells. Acad Radiol. 2002;9:S540-3. doi. org/10.1016/S1076-6332(03)80287-8. PubMed PMID: 12188332.
11. Bushberg JT, Boone JM. The essential physics of medical imaging: Lippincott Williams \& Wilkins; 2011.

12. Ohnishi K, Hokari S, Shutou H, Ohshima M, Furuichi N, Goda M. Origin of most primitive mRNAs and genetic codes via interactions between primitive tRNA ribozymes. Genome Inform. 2002;13:7181. PubMed PMID: 14571376.

13. Tobita T, Izumi K, Feinberg SE. Development of an in vitro model for radiation-induced effects on oral keratinocytes. Int J Oral Maxillofac Surg. 2010;39:364-70. doi.org/10.1016/j. ijom.2009.12.020. PubMed PMID: 20080035. PubMed PMCID: 2859991.

14. Tirro E, Consoli ML, Massimino M, Manzella L, Frasca $F$, Sciacca $L$, et al. Altered expression of C-IAP1, survivin, and Smac contributes to chemotherapy resistance in thyroid cancer cells. Cancer Res. 2006;66:4263-72. doi.org/10.1158/00085472.CAN-05-3248. PubMed PMID: 16618750.

15. Sandulache VC, Skinner HD, Wang Y, Chen Y, Dodge CT, Ow TJ, et al. Glycolytic inhibition alters anaplastic thyroid carcinoma tumor metabolism and improves response to conventional chemotherapy and radiation. Mol Cancer Ther. 2012;11:1373-80. doi.org/10.1158/1535-7163. MCT-12-0041. PubMed PMID: 22572813. PubMed PMCID: 3856684.

16. Samani F, Monfared AS, Zabihi E, Khafri S, Karimi $\mathrm{M}$, Akhavan Niaki $\mathrm{H}$. Evaluation of the effects of paederus beetle extract and gamma irradiation on HeLa cells. Iran J Basic Med Sci. 2014;17:3036. PubMed PMID: 24904724. PubMed PMCID: 4046238.

17. Hizoh I, Farsang C, Kiss I, Kónya L, Jánoskuti L, Ujhelyi L. Programmed cell death as a pathogenic factor for contrast nephropathy: radiocontrast-induced renal tubular cell apoptosis in vitro. Semmelweis University; 2005.

18. Zito G, Richiusa P, Bommarito A, Carissimi E, Russo L, Coppola A, et al. In vitro identification and characterization of CD133(pos) cancer stemlike cells in anaplastic thyroid carcinoma cell lines. PLoS One. 2008;3:e3544. doi.org/10.1371/ journal.pone.0003544. PubMed PMID: 18958156. PubMed PMCID: 2568821.

19. St Germain C, Niknejad N, Ma L, Garbuio K, Hai T, Dimitroulakos J. Cisplatin induces cytotoxicity through the mitogen-activated protein kinase pathways and activating transcription factor 3 . Neoplasia. 2010;12:527-38. doi.org/10.1593/neo.92048. PubMed PMID: 20651982. PubMed PMCID: 2907579. 